\title{
Os sentidos da economia solidária: reflexões sobre um curso de formação ${ }^{1}$
}

\author{
Felipe Marques Carabetti Gontijo2 \\ Orcid: https://orcid.org/0000-0001-6650-0305 \\ Ana Paula Paes de Paula ${ }^{2}$ \\ Orcid: https://orcid.org/0000-0001-8035-472X
}

\section{Resumo}

Neste artigo, apresentam-se reflexões sobre um curso de Formação em Economia Solidária da Senaes, que é parte de uma política pública do Governo Federal para Economia Solidária (ES) no Brasil. Tendo como referência a relação entre o movimento social e o Estado, buscou-se perceber os sentidos da economia solidária nesse processo de formação. Considerando-se os objetivos, valores e princípios manifestados pelo movimento da ES na literatura e nos documentos coletados, identificou-se a ES crítica e a ES neoliberal. A pesquisa empírica ocorreu em duas etapas: uma documental e outra etnográfica, que abordaram os três momentos diferentes do curso: pré-concepção, concepção e implementação. Os dados foram examinados por meio da análise de conteúdo e, após esse percurso, foi possível perceber que, de forma geral, há uma consonância de sentidos nos três momentos identificados em torno da ES crítica e uma prática pedagógica apropriada nos espaços de sala de aula. Constatou-se ainda uma moderação do discurso feita pela Senaes que, a princípio, não descaracteriza o movimento da ES, mas apresenta potencial risco no que diz respeito ao desvio de seu ideário e objetivos. Nas considerações finais, retomam-se os pontos de destaque da pesquisa e discutem-se brevemente os limites e possibilidades dessas ações promovidas via Estado.

\section{Palavras-chave}

Economia solidária - Formação e educação críticas - Emancipação - Políticas públicas.

\footnotetext{
1- 0 presente artigo é parte da pesquisa de mestrado de Felipe Marques Carabetti Gontijo, orientada por Ana Paula Paes de Paula, no âmbito do Centro de Pós-graduação e Pesquisa em Administração (CEPEAD) da Universidade Federal de Minas Gerais (UFMG). Agradecimentos ao CNPq, à Capes e a Fapemig pelo apoio à pesquisa.

2- Universidade Federal de Minas Gerais, Belo Horizonte, MG, Brasil. Contatos: felcarabetti@yahoo.com.br; appaula@face.ufmg.br.
} 


\section{The meanings of solidarity economy: reflections on a training course}

\section{Abstract}

This article presents reflections on a Training Course in Solidarity Economy by Senaes, which is part of a public policy conducted by the Federal Government for Solidarity Economy (SE) in Brazil. Based on the relationship between the social movements and the State, the effort is to grasp the meanings of solidarity economy along this process of formation. Considering the objectives, values, and principles expressed by the SE movement in the literature and in the documents gathered, two strands are identified: critical SE and neoliberal SE. The empirical research took place in two steps: a documentary and an ethnographic step, addressing the three different moments of the course: pre-conception, conception, and implementation. Data were examined through content analysis and, once the course was completed, it was possible to perceive that, in general, there is a consonance of meanings in the three moments identified around the critical SE and an appropriate pedagogical practice in the classroom. In addition, we found a moderation of the speech by Senaes, and, in principle, it does not mischaracterize the SE movement, but presents a potential risk of deviating from its ideals and objectives. In the final considerations, the highlights of the research are shown followed by a brief discussion of what seems to be the limits and possibilities of actions like these promoted through the State.

\section{Keywords}

Solidarity economy - Critical education and formation - Emancipation - Public policies.

\section{Introdução}

Nos últimos trinta anos da história do Brasil, tornou-se crescente o interesse por iniciativas no campo da economia solidária (ES), bem como por questões que envolvem a formação de ativistas e implementadores de políticas nessa área. Entre os motivos para isso, estão: 1) o crescimento do número de empreendimentos econômicos solidários no país nos últimos anos (IPEA, 2016); 2) a aposta na ES para geração de trabalho e renda em momentos de crise do emprego (POCHMANN, 1999); e, 3) a expansão dos movimentos internacionais e locais que buscam construir alternativas para a globalização neoliberal e seus efeitos indesejáveis (CASTELLS, 2013). A recente mudança do governo e dos rumos do país nos convida a algumas reflexões acerca da ES e sua atuação via Estado.

A Secretaria Nacional de Economia Solidária (Senaes), que completa quinze anos de existência em 2018, já foi considerada um indicador do fortalecimento da ES no país. Se esse reconhecimento é, para alguns, motivo de comemoração, para outros a aproximação da esfera da política formal é fonte de preocupação e suscita reflexões e críticas sobre a ES. Em relação às críticas internas, a preocupação é de que essa aproximação do movimento 
da ES em relação ao Estado possa incorrer em cooptação do mesmo por parte de políticos profissionais ou de interesses que se fazem influentes nessas arenas. Sobre as críticas externas, questiona-se o potencial da ES para se colocar como alternativa ao capitalismo.

Sinteticamente, a discussão sobre cooptação pode ter como referência as reflexões sobre a forma de incorporação de novos atores políticos na política formal brasileira ao longo do século XX. Há, pelo menos, duas interpretações dessa incorporação: 1) como a cooptação desses novos atores por parte do Estado (SCHWARTZMAN, 1970); ou, 2) a constituição e expansão paulatina do que se chama de mercado político (REIS, 2000). A primeira entende a participação política feita por meio da cooptação de lideranças políticas pelo centro do poder, em detrimento da representação social e da ação direta. A segunda não parte do mesmo princípio de oposição entre Estado e sociedade e percebe a "incorporação domesticada de novas forças sociais ao processo político" (REIS, 2000, p. 255) como o início do processo de constituição do mercado político e de um período de "institucionalização do poder", ou state-building, que fazem parte do processo de constituição de uma democracia liberal e plural.

A crítica externa questiona o potencial que a ES teria para efetivamente se colocar como alternativa ao capitalismo (GAIGER, 2003; DAGNINO; NOVAES, 2007; WELLEN, 2008), além do risco de que outros setores e grupos possam se apropriar do discurso da ES para fins diversos e até mesmo contrários aos seus. Essa apropriação do discurso pode servir para dois objetivos diferentes, mas não excludentes. 0 primeiro é a intensificação da precarização das relações trabalhistas, com o intuito apenas de gerar ganhos econômicos aos donos das cooperativas, ou aos contratantes de seus serviços (LIMA, 2002). 0 segundo afigura-se como forma de o Estado renunciar à garantia de direitos historicamente conquistados de cidadania, como o acesso ao emprego formal (BARBOSA, 2007).

Diante desses dilemas e relações complexas, questiona-se qual avaliação se pode fazer desse fenômeno a partir da experiência de inserção no Governo Federal no campo da ES. Com o intuito de contribuir para uma avaliação crítica dessa experiência, selecionouse uma política pública advinda da Senaes para ser estudada: um curso de Formação em Economia Solidária. Para a escolha da política, levou-se em conta a relevância da questão da formação no âmbito da ES, tida como tema prioritário na Conferência Nacional de Economia Solidária (CONFERÊNCIA..., 2010).

As perguntas que orientaram a pesquisa foram: Examinando as noções de emancipação que emergem do curso estudado, qual é a interpretação e o sentido ES que prevalece? Esses sentidos da ES sofrem alguma diferenciação nos três momentos do curso (pré-concepção, concepção do curso e implementação)?

Dessa forma, tendo como referência a relação entre o movimento social e Estado, buscou-se avaliar o potencial e os limites desse curso nos próprios termos do movimento de ES, ou seja, tomando como orientação os valores anunciados na sua carta de princípios (FÓRUM..., 2010). Importante ressaltar, no entanto, que as considerações feitas a partir da presente pesquisa não permitem, ou pretendem, uma resposta que subsidie um posicionamento definitivo e generalizante perante as questões levantadas, mas visam contribuir para a reflexão a partir de uma avaliação particular contextualizada.

Além dessa introdução, o presente artigo conta com mais cinco partes. Na segunda parte apresenta-se a disputa de sentidos na Economia Solidária, as diferentes concepções 
e o estabelecimento de uma dialética entre posições liberais e revolucionárias, definindo o argumento central do trabalho. Na terceira parte, discutem-se as relações entre a formação e educação críticas e Economia Solidária. Na quarta parte, apresenta-se o objeto do estudo. Na quinta parte, descrevem-se os aspectos metodológicos da pesquisa e realiza-se a análise de dados. Na sexta parte, são feitas considerações finais destacando os principais achados da pesquisa e suas relações com estudos afins.

\section{Economia solidária e a disputa de sentidos}

Paul Singer (2002), um dos principais estudiosos brasileiros sobre ES, não a caracteriza exatamente como um conceito, mas antes como um movimento histórico, social e político, igualmente fazem Costa e Jesus (2017). Coraggio (2007), Gaiger (2007), Laville (2006) e Lima (2009) reconhecem que tal entendimento é polêmico pela variedade de interpretações acerca da ES, mas analisando a trajetória do Fórum Brasileiro de Economia Solidária (FBES) e a criação da Senaes sustentam que tal caracterização é válida.

De acordo com o Singer (2002), a ES tem em suas raízes a dialética entre a solidariedade e a competição na economia e entre a autogestão e a heterogestão nas organizações. Singer defende que a história da ES remonta ao cooperativismo revolucionário do século XIX, que deu origem aos princípios cooperativistas e inspiraram o cooperativismo de consumo, de crédito e de compras e vendas, fomentadores das experiências de ES ao longo do século XX.

No entanto, a consulta à literatura sobre o tema revela que as teorias e as práticas recentes a respeito do que se poderia chamar de forma geral de ES possuem diferentes nomenclaturas. De acordo com Motta (2004, p. 65), o uso de diferentes termos não ocorre sem motivo ou de forma neutra, uma vez que, "diferentes visões estão implicadas no uso dos diferentes termos, muitas vezes dando forma a disputas em torno de projetos", conforme também constatam Costa e Jesus (2017).

Cançado (2005, p. 2) identifica três abordagens acerca do conceito de ES. Na primeira delas, inspirada por Marcos Arruda, "a economia solidária pode ser considerada como 'um outro modo de vida', em que valores percebidos vão muito além da competição característica da sociedade capitalista”. A segunda abordagem, baseada no pensamento de Paul Singer (2002), entende o movimento da ES como uma alternativa ao modo de produção vigente e crê ser possível outro tipo de relação entre os seres humanos para além da divisão internacional do trabalho. Já a terceira abordagem, fundamentada em Coraggio (2007) e Gaiger (2007), caracteriza a ES como uma alternativa encontrada pelos setores populares para sobreviverem ao neoliberalismo.

Importante notar que as organizações geradoras de trabalho e renda, ainda que não tipicamente capitalistas, como ocorre no caso de empreendimentos de ES, frequentemente operam de forma marginal, inseridas e dependentes do modo de produção capitalista e por isso ainda não conformam um novo modo de produção global (ADAMS, 2007). Essas iniciativas podem ocultar uma forma de exploração na articulação do trabalho informal com a produção capitalista ao substituírem coletivamente a forma assalariada aumentando 
a precarização do trabalho. Por essas razões, dentre as perspectivas que disputam espaço político, identificou-se uma abordagem de ES que se inspira nas diretrizes neoliberais.

Apesar da fragmentação e pluralidade verificadas a respeito do conceito de ES na literatura, entendeu-se que é possível caracterizar duas vertentes principais, estabelecendo uma dialética entre posições liberais e revolucionárias de ES para orientar esse artigo: 1) ES crítica, que busca transformação social ampla, ligada à ideia de autonomia, e que ultrapassa o aspecto econômico para alcançar também as esferas política, cultural, ambiental, de gênero etc.; e, 2) ES neoliberal, que se restringe à renda e capacidade de consumo, de reprodução do capital, tendo como foco a questão econômica.

Vale sublinhar as diferenças entre essas duas concepções de ES. Enquanto uma entende a emancipação a partir da inserção econômica, mais especificamente a inserção pela capacidade de consumo de determinado grupo na sociedade, a outra crê que emancipação seja algo além. Na perspectiva da ES crítica, a luta se dá por outra forma de se relacionar com o mundo, de se organizar para produzir, consumir, gerir e viver. São três as condições básicas para se falar sobre emancipação: (1) a autonomia crítica efetiva, que concerne à capacidade de avaliar as estruturas sociais nas quais os atores estão imersos; (2) a interação pelo diálogo e a intercompreensão, que diz respeito ao reconhecimento do status de sujeito no outro interagente; (3) a argumentação que é relativa à maneira pela qual se dá essa interação, extirpando a violência ou qualquer forma de coerção, privilegiando o diálogo e a construção intersubjetiva. A ES neoliberal, por outro lado, pretende servir como possibilidade de geração de trabalho e renda, enfatizando quase exclusivamente as condições econômicas das práticas solidárias, sem que se busque mudanças estruturais ou de paradigma no seio da sociedade.

\section{Formação e educação críticas e economia solidária}

Espera-se que diversas habilidades e capacidades sejam desenvolvidas e refinadas nos sujeitos em ambientes de formação e educação, formais ou não. A depender do que se espera dos sujeitos na sua vida social, política e no trabalho, as habilidades e competências que se creem importantes podem variar significativamente. Nas sociedades capitalistas, os requisitos da técnica e de obediência têm primazia, assim como a hierarquia, o individualismo e a competição, com a valorização do treinamento e adestramento, no que se refere à educação para o trabalho. No âmbito da ES, por sua vez, valores como autonomia, solidariedade, coletividade e cooperação ganham destaque, abrindo espaço para outro tipo de formação educacional e profissional.

Segundo Gadotti (2009), a ES está relacionada de forma estreita com a educação transformadora. Considerando que os empreendimentos solidários buscam a organização autogestionária, eles demandam uma educação para cooperação, uma pedagogia da economia solidária que envolve uma formação política que engendre a cultura solidária, a alteridade e o desenvolvimento humano. Gadotti (2009) reconhece a importância da educação popular e do pensamento de Paulo Freire na edificação dessa pedagogia, abrangendo conteúdos básicos como cultura sobre empreendimentos solidários e constituição de redes e cooperativas, participação cidadã, trabalho emancipatório, direitos sociais e autogestão, 
contemplando, sobretudo, experiências concretas. Metodologias participativas, processos autogestionários e tecnologia social também têm grande importância. Nessa perspectiva, a qualificação profissional vem acompanhada de qualificação social, formando um mosaico de habilidades básicas para a cidadania e o trabalho e habilidades específicas nas ocupações envolvidas, bem como habilidades de gestão, em especial de autogestão.

Singer (2005), em suas reflexões sobre ES e educação, entende que as pessoas educadas no capitalismo devem ser reeducadas para a prática da ES. 0 desafio é, no entanto, que essa reeducação seja coletiva para fazer funcionar uma lógica cooperativa. Tal reeducação passa pela vivência e experimentação prática, além da reflexão teórica, pois, a mudança de comportamento e o sentimento que fundamentará a ES emergirão da prática, da vivência. Assim como para Gadotti (2009), para Singer (2005) um dos pontos cruciais da formação e educação em ES é o ensino e a prática da autogestão. Segundo o autor, a imbricação da ES com Educação é tão profunda que a ES é compreendida como um ato pedagógico em si mesmo, que ao mesmo tempo em que propõe uma nova prática social, busca compreendê-la dinamicamente. 0 mesmo ocorre na imbricação da ES e a prática, de forma que "a única maneira de aprender a construir a Economia Solidária é praticando-a” (SINGER, 2005, p. 19).

0 exame da literatura revela que não há exatamente um referencial teórico específico sobre a educação para a ES no Brasil, pois se constatou relativa escassez de referências em consulta feita aos portais de periódicos nacionais (ZITKOSKI, 2010; CALBINO, 2013). 0 que os pesquisadores, como, por exemplo, Adams (2007), revelam é que as práticas pedagógicas nesse âmbito recorrem ao substrato histórico da educação popular e da teologia da libertação que circundou os movimentos sociais e organizações não governamentais desde a década de 1970, demonstrando a centralidade de Paulo Freire enquanto pensador nesse domínio. Nesse contexto, busca-se "a defesa da educação como um ato de diálogo, a noção de uma ciência aberta às exigências ética de qualidade de vida, com um planejamento comunitário e participativo" (ADAMS, 2007, p. 170). Além disso, a concepção freireana enfatiza a dialética entre caráter domesticador e emancipador da educação, sendo que esta, em uma atividade de trabalho que busque emancipação pessoal ou social, implica em escolher uma concepção de ser humano e uma escala de valores que tragam o conteúdo ético e político da ES. Reunindo os pontos levantados pelos pensadores que relacionaram educação e ES, apontamos as seguintes diretrizes: (1) educação como ato de diálogo; (2) autoaprendizagem mútua; (3) ciência aberta às exigências éticas de qualidade de vida; (4) tecnologia social; (5) planejamento comunitário e participativo; (6) caráter emancipador; (7) autogestão; e (8) vivência prática.

Devido à reduzida literatura sobre o tema e uma vez que um dos sentidos de ES mobilizados no presente trabalho remete à mudança social ampla, entendemos que outras contribuições importantes para o aprofundamento desse debate podem ser trazidas da perspectiva crítica de educação. De acordo com Giroux (1999), a educação buscada na perspectiva capitalista e neoliberal enfatiza pedagogias da Escola Tradicional, que é disciplinadora; da Escola Nova, que prima pela adaptação e da Escola Técnica, que busca formar em habilidades úteis ao desempenho de funções mais ou menos definidas pelo mercado. Segundo o autor, os tradicionalistas têm se ancorado na tentativa de encontrar 
princípios universais de educação que estejam "enraizados no espírito do instrumentalismo e do individualismo automáticos” (GIROUX, 1986, p. 16). Em sua concepção de escola, são ignoradas questões como poder, conhecimento e ideologia. A escola é por eles entendida apenas como um local de instrução, onde o mais importante são os conteúdos tratados. Já os pensadores da Escola Nova creem que os alunos devem exercer papel ativo em sua aprendizagem para exercitarem sua capacidade de criação e adaptação às novas condições de vida, "aprendendo a aprender" (GIROUX, 1986). Com os tecnicistas houve uma volta aos princípios tradicionais da educação, buscando-se o ajustamento do aluno às necessidades laborais, seguindo-se as diretrizes da psicologia behaviorista. Cabe à escola ensinar a fazer, mediante os princípios de racionalidade, eficiência e produtividade.

A perspectiva crítica em educação, por outro lado, se baseia na relação dialética escola-sociedade. Abre-se espaço para a resistência das pessoas à ordem dominante e à criação de uma nova ordem, possibilitando a mudança nas estruturas sociais. A agenda de trabalho da perspectiva crítica é composta pela teoria crítica de currículo (SILVA, 1999), análise do currículo oculto (GIROUX, 1986), análise crítica dos livros didáticos (NOSELLA, 1979; FREITAG, 1993; FARIA, 1994) e relação dialógica entre professor e aluno (ENGUITA, 1989). A teoria crítica do currículo surge como contraponto à teoria do currículo. Enquanto esta se baseava nos princípios da administração científica de Taylor, buscando organizar o currículo de modo que o produto do ensino (aluno) pudesse ser planejado no maior número de detalhes e padronizado, a teoria crítica busca descortinar as ideologias de classe e os mecanismos de reprodução cultural e social, privilegiando o estudo de questões como emancipação, libertação, resistência e conscientização (SILVA, 1999).

A educação crítica se baseia na consciência coletiva e solidária do homem, tendo como pilar a capacidade do educador de "assumir a ingenuidade dos educandos para poder, com eles, superá-la” (FREIRE, 1989, p. 15). Isso significa que o professor deve respeitar a percepção de realidade do aluno e, a partir dela, buscar o desenvolvimento da consciência crítica. A educação crítica é um processo solidário na medida em que estabelece a troca de papéis entre educador e educando em um processo constante de superação e confronto ideológico. Por fim, ao educador crítico cabe questionar os conteúdos programáticos e estruturas das instituições de ensino e da sociedade, bem como denunciar todas as formas de opressão e reprodução das estruturas de dominação, incluindo a si mesmo no processo de avaliação crítica (SILVA, 2004).

As principais premissas da concepção crítica do ensino podem ser resumidas, com base em Silva (2004), Perriton e Reynolds (2004), McLaren (1997), Freire (1989; 2002), nos seguintes itens: (1) o processo de aprendizagem é analisado considerando-se o contexto histórico, político, econômico e social; (2) A sociedade também educa, não cabendo somente à escola esta função; (3) as escolas não são instituições neutras. Elas são o lócus de disputa política, econômica, cultural e social; (4) as escolas devem ser analisadas dialeticamente enquanto estruturas que reproduzem as desigualdades sociais e o discurso hegemônico, ao mesmo tempo em que criam alternativas para a resistência e libertação destas dominações; (5) a educação é uma formação tanto técnica quanto moral; (6) a unidade de análise é social e não individual, dando ênfase aos conceitos de comunidade 
e construção social da realidade; e (7) o objetivo é a emancipação dos grupos sociais e o desenvolvimento de uma sociedade mais igualitária.

As discussões acerca da formação e educação críticas e ES apontam para os aspectos da educação formal e informal que são relevantes para a reflexão sobre a formação para a mudança social ampla. As diretrizes da educação para ES e as premissas da concepção crítica da educação auxiliam a avaliar a o objeto em questão para além da consonância dos sentidos da ES ao longo do caminho da política. Sobretudo, permitirá, oportunamente, uma análise crítica da sala de aula que leve em conta não somente os conteúdos, mas também outros aspectos envolvidos no processo pedagógico do curso.

\section{O curso de formação em ES}

0 objeto de estudo selecionado foi o Curso Estadual de Formação de Formadores em ES oferecido pelo Centro de Formação em Economia Solidária do Sudeste (CFES-SE), parte do Programa Economia Solidária em Desenvolvimento (PESD) da Senaes e do Plano Plurianual (PPA) do Governo Federal de 2008-2011. A escolha desse curso específico baseou-se na importância da formação dentro do campo da ES, na interação entre diferentes atores na consecução da política e na facilidade geográfica para realização da pesquisa. 0 curso abordado nessa investigação ocorreu na região metropolitana de Belo Horizonte, entre os meses de março e maio de 2011 em três módulos separados. Cada módulo ocorria em três dias consecutivos (sexta, sábado e domingo). Durante as manhãs e tardes ocorriam as atividades formativas, enquanto que à noite promoviam-se espaços de convivência e descanso.

A Senaes e o Conselho Nacional de Economia Solidária (CNES) foram criados em 2003, oriundos de mobilizações de nível internacional-local (Grupo de Trabalho Brasileiro de Economia Solidária formado no Fórum Social Mundial de 2001) e das Plenárias de Economia Solidária. No mesmo mês de criação da Senaes e do CNES, por parte do governo Lula, o movimento de ES constituiu o Fórum Brasileiro de Economia Solidária (FBES). Pode-se dizer que esses são os três atores, juntamente com o Instituto Marista de Solidariedade (IMS), envolvidos diretamente no curso estudado.

O IMS é o realizador do curso estudado e responsável pelo CFES-SE. 0 instituto constitui-se em uma associação civil sem fins lucrativos e tem por finalidade "criar, congregar, dirigir e manter instituições que visem à beneficência e a assistência social, a promoção humana, a educação, o ensino e a cultura" (IMS, 2008, p.1-2). Além disso, o instituto é parceiro em várias ações realizadas no campo da ES e integra os fóruns da base do movimento de economia solidária nas instâncias locais e na instância nacional (FBES).

\section{Aspectos metodológicos e análise de dados}

A pesquisa ocorreu em uma etapa documental e outra etnográfica que abordaram os três momentos diferentes do curso (pré-concepção, concepção e implementação). Para os dois primeiros momentos, utilizou-se a pesquisa de tipo documental (SÁ-SILVA; ALMEIDA; GUINDANI, 2009; BARDIN, 2009), e para o curso propriamente dito, utilizou-se a etnografia 
na educação (ANDRÉ, 2007). O processo de coleta de dados nos momentos do curso desenrolou-se por meio da observação participante e de conversas individuais e em grupo. A apreensão dos sentidos ocorreu nos momentos de interação entre o pesquisador e os demais participantes do curso, na sala de aula e nos espaços informais (café da manhã, almoço, intervalos, forró com caldo, barzinho, fogueira etc.). Empregou-se a análise de conteúdo (MINAYO, 1994, BARDIN, 2009) para organizar as informações e elaborar os dados.

A partir de uma leitura flutuante do corpus documental selecionado para análise entendeu-se que a categorização dos temas destacados nos documentos poderia ser feita a partir dos dois sentidos (categorias a priori) identificados no constructo emancipação que se estendem para a ES: 1) ES crítica, que busca transformação social ampla, ligada à ideia de autonomia, e que ultrapassa o aspecto econômico para alcançar também as esferas política, cultural, ambiental, de gênero etc.; e, 2) ES neoliberal, que se restringe à renda e capacidade de consumo, tendo como foco a questão econômica.

$\mathrm{Na}$ consecução dos procedimentos da análise de conteúdo, percebeu-se a permanência das duas categorias a priori e a emergência de duas subcategorias, ambas referentes à ES crítica: (1) busca por emancipação; e (2) motor e mudança da visão de mundo e das práticas dos sujeitos. A categoria relativa à ES neoliberal permaneceu sendo basicamente a ES como melhoria das condições de vida sem romper com a lógica e/ou valores do capitalismo.

A subcategoria busca pela emancipação é instruída por três noções de emancipação. A primeira remete à superação da alienação no trabalho capitalista. A segunda é política-pragmática e denota preocupações práticas com a organização e o movimento de ES, bem como sua relação com o Estado, com outros órgãos e mesmo internamente. Por fim, a terceira, é utópica-ontológica e trata da maneira de entender/olhar o trabalhador como sujeito histórico a promover as mudanças estruturais.

A subcategoria motor e mudança da visão de mundo e das práticas dos sujeitos reflete a ideia de que a ES ao mesmo tempo requer e potencializa uma visão de mundo diferente da capitalista. Entende-se que essa mudança de perspectiva passa pelas mudanças das relações sociais, das relações dos sujeitos com o meio-ambiente e das relações dos sujeitos com as atividades econômicas, produtivas, de distribuição de riquezas e de consumo, possibilitando uma outra qualidade de vida e tornando possível um outro mundo, diferente do produzido pelo capitalismo. Muitas vezes o índice desse outro mundo foram as críticas diretas ao capitalismo e àquilo que lhe é atribuído como efeito.

A categoria ES neoliberal remete à proposta de busca por benefícios econômicos, materiais e outros advindos desses, sem romper com as lógicas ou valores capitalistas. Dentro desse contexto, a reunião de pessoas para o exercício de alguma atividade econômica é interessante principalmente desde o ponto de vista dos benefícios fiscais, da competitividade, da eficiência, da diminuição de custos, do aumento da renda, do aumento do poder de compra, da inserção em diferentes mercados consumidores, do ganho de poder de barganha em negociações, entre coisas da mesma natureza.

Para proceder com a análise dos dados, separou-se o corpus da pesquisa de acordo com o que anteriormente chamamos de três momentos da política: (a) textos de referência (documentos oficiais), pré-concepção; (b) material do curso, concepção; e (c) sala de aula (espaços do curso), implementação. 
Nos textos de referências, notou-se pouca variação do que se entende por ES. Em geral, as variações percebidas ocorreram mais pelas diferentes propostas dos documentos do que pela diferença entre as perspectivas de emancipação. Em todos os textos analisados encontraram-se registros que levaram apenas à ES crítica, abordando todas as suas subcategorias. Não obstante, notou-se uma moderação do discurso no âmbito da Senaes, que sugere limitações da atuação da ES via Estado.

Os sentidos da emancipação referentes à subcategoria busca por emancipação emergiram em suas três noções: superação da alienação, dimensão político-pragmática e utópico-ontológica. A forma da superação da alienação despontou de três maneiras: do trabalhador em relação aos meios de produção, ao conhecimento e ao poder decisório. A emancipação político-pragmática emergiu nas reflexões acerca da organização e atuação do movimento de ES. As preocupações, nesse caso, eram as seguintes: fortalecimento do movimento a partir de canais de participação e mobilização; busca por visibilidade política da ES para sua incorporação na agenda política do país; e construção de uma relação com o Estado em que haja canais de participação efetiva, com acompanhamento e controle social das políticas. A emancipação utópico-ontológica foi notada naqueles nomeados como sujeitos históricos: os trabalhadores, que são capazes de lutar por seus direitos e promover mudanças estruturais na sociedade.

A subcategoria forma como o projeto econômico solidário se posiciona frente ao capitalismo emerge na comparação dos textos da Senaes com os demais. Enquanto os textos do FBES, do IMS e do CNES localizam claramente a ES em oposição ao capitalismo, nomeando-o e criticando-o, os textos da Senaes, exceto por uma passagem de um documento em seu sítio eletrônico (BRASIL, s/d), colocam a economia solidária como alternativa ao modelo vigente sem nomeá-lo, ou criticá-lo de forma explícita:

A economia solidária nega a competição nos marcos do mercado capitalista que lança trabalhador contra trabalhador, empresa contra empresa, país contra país, numa guerra sem tréguas em que todos são inimigos de todos e ganha quem for mais forte, mais rico e, frequentemente, mais trapaceiro e corruptor ou corrupto. (FÓRUM..., 2010, p. 5).

Economia Solidária é um jeito diferente de produzir, vender, comprar e trocar o que é preciso para viver. Sem explorar os outros, sem querer levar vantagem, sem destruir o ambiente. Cooperando, fortalecendo o grupo, cada um pensando no bem de todos e no próprio bem. (BRASIL, 2011, p. 1).

Entende-se que essa adoção de um discurso mais palatável guarda relação com o intento de ampliação de parcerias, mas também pode representar um indício de limitação da atuação da ES desde dentro do Estado.

Em relação ao material do curso, a despeito de sua heterogeneidade, considera-se que não houve grande variação do que se entende por ES e dos sentidos da emancipação. De forma geral, prevalece uma vez mais a ES crítica. Há a emergência de duas posturas diferentes em relação à produção, consumo e comercialização na ES, em que uma abordagem centra mais na questão da produção, representada pelas ideias de Singer 
(2002), e outra que considera também a comercialização e o consumo como atividades fundamentais para as pretensões da ES que remete aos escritos de Mance (2000). Não obstante, entende-se que essa variação entre um e outro projeto nos materiais se deu mais por questões pragmáticas (dificuldade de comercialização) e não chega a caracterizar uma disputa entre diferentes projetos de ES dentro do movimento.

0 consenso ocorre em torno das noções de autonomia e autogestão, compromisso com a sustentabilidade ambiental, solidariedade, democracia e participação, ser humano como finalidade da atividade econômica, valorização do saber popular/do trabalhador, e valorização e respeito à diversidade. A presença da ideia da ES em sua dimensão pedagógica também está presente nos materiais, destacando-se Freire e sua pedagogia da autonomia.

Fato que ainda não havia ocorrido foi a emergência da ES neoliberal e os sentidos de emancipação que a ela correspondem. 0 que possibilitou a qualificação dos trechos do material do curso como pertencentes a essa subcategoria é o entendimento de que, em parte do material, há primazia dos ganhos econômicos ou de possíveis benefícios materiais em detrimento dos demais valores da ES. Além disso, também a ideia de que a emancipação possa ser alcançada apenas, ou principalmente, via renda e poder de compra e de que a economia solidária serve para dirimir os efeitos nefastos do neoliberalismo:

Nas cidades, cooperação, solidariedade e trabalho agora são soluções para enfrentar o desemprego. Eu não tenho medo mais do desemprego, isso daí acabou pra mim. (VÍDEO INSTITUCIONAL, 1'16”).

Um avanço que vai representar mais postos de trabalho, mais inclusão social e novo vigor na retomada da produção. (VÍDEO INSTITUCIONAL, 13’30”).

A partir do primeiro trecho destacado, seria possivel entender a ES como uma forma de autoemprego coletivo. Sabe-se que no Brasil o marco jurídico da ES (do cooperativismo) não dá conta de suas especificidades e que, devido a isso, mais da metade dos Empreendimentos Econômicos Solidários (EES) constituídos são informais (BRASIL, 2007). Adotar o discurso da ES, sem uma contrapartida de luta e organização política, jurídico-legal e social, uma luta coletiva, seria aceitar essa condição atual de precariedade da maioria dos trabalhadores econômicos solidários admitindo o autoemprego coletivo como uma saída para a situação de desemprego.

Já o segundo trecho dá a entender que a inclusão social adviria da criação dos postos de trabalho e, pode-se inferir, da geração de renda. Essa ideia parte, por um lado, de uma constatação da realidade brasileira, mas está inserida, também, na concepção liberal da cidadania e inclusão social. Além disso, o entendimento de que a luta por uma mudança de perspectiva de vida depende do esforço individual sem denotar que a luta tem uma dimensão coletiva é parte de um discurso ao mesmo tempo voluntarista e liberal, contradizendo os sentidos da emancipação da ES crítica, como o trecho a seguir: 
Viver dessa maneira depende do esforço de cada um, da vontade de experimentar, de ter iniciativa e esperança de que a sua vida pode mudar e depende principalmente da disposição de incorporar os princípios de solidariedade, igualdade e justiça. (CECCON, s./d.).

Dentro de um contexto mais amplo, percebe-se que os trechos transcritos acima, e outros entendidos como parte da ES neoliberal, não são exatamente parte do discurso que defende esse sentido de ES, mas uma estratégia de marketing e sensibilização com enfoque mais agudo nos benefícios econômicos da ES. Apesar disso, ao assistir apenas ao Vídeo institucional e ao documentário Outra economia acontece a dúvida sobre qual sentido da ES é defendido não se desfaz completamente. Por isso, pelo risco que tal ambiguidade representa e pela fragilidade da ES e de seus participantes no Brasil, decidiu-se, mesmo após a análise contextualizada dos trechos, classificá-los como ES neoliberal.

Em relação à sala de aula, não houve menções que foram entendidas como referentes ES neoliberal, apenas à ES crítica. Os assuntos tratados foram: módulo I - como funciona a sociedade (exploração e luta de classes) e educação popular; módulo II - desenvolvimento sustentável solidário e o paradigma econômico da abundância; e módulo III - relação entre educação popular e ES e questões de gênero. A respeito da ES crítica, emergiu tanto a subcategoria 1 (em suas três noções) quanto a subcategoria 2. Entretanto, o que se gostaria fazer notar é que nos momentos de sala de aula foi possível perceber inter-relações entre as subcategorias da ES crítica, oportunidade para entender como essas noções, até aqui analiticamente separadas, se unem para dar origem a formações mais complexas.

0 sentido da emancipação que coloca a ES como superação da alienação do trabalho capitalista foi a noção mais presente durante o curso. Crê-se que isso ocorreu principalmente pelo fato de essa noção de emancipação estar mais presente no cotidiano daqueles que vivenciam a ES, sobretudo para aqueles que o fazem a partir dos empreendimentos produtivos solidários. Certamente esse é um dos grandes objetivos da luta e possível fator de identificação entre os partícipes da ES.

A identificação e o compartilhamento de formas semelhantes de sofrimento e dificuldades, não obstante a diversidade interna, são a condição que possibilita o reconhecimento de si como sujeito da história, remetendo à noção utópico-ontológica. Esse sujeito trabalha e fica apenas com uma parte do que produz da riqueza, de modo que o produto de seu trabalho é alienado de si. A mudança a ser perpetrada por esses sujeitos se coloca em um horizonte de lutas não individuais, mas coletivas e o entendimento da luta coletiva, que faz referência à noção político-pragmática, guarda espaço para a subjetividade e para a diversidade. Entende-se que é por meio da luta coletiva que se poderão criar condições para a individualidade e para a diversidade serem vivenciadas e desenvolvidas. Essa imbricação remete a um entendimento da dupla natureza do ser humano: individual e social. Nessa perspectiva, autonomia e emancipação são categorias concebidas de forma relacional e dialética, ou seja, ninguém pode ser autônomo ou emancipado individualmente, assim como um grupo não pode ser considerado emancipado se seus sujeitos não o são.

Nota-se que há também questões materiais que se impõem aos sujeitos e que influenciam suas vivências e suas possibilidades de ação, além da percepção dos problemas 
como coletivos. Entende-se que se por um lado é necessário mudar a visão de mundo e os valores para transformar a realidade, por outro, há condições materiais que influenciam formas de pensar e agir no mundo. A mudança se daria de forma conjunta na realidade concreta e na adoção de outros valores e visão de mundo sempre com diversos limites e contradições. Trata-se de um processo dialético e paulatino de mudança social que leva em conta tanto uma dimensão ideológica quanto material.

Extrapolando, por fim, os sentidos da ES e a consonância entre eles é perceptível que o conteúdo do curso privilegia as questões relativas à emancipação, libertação, resistência e conscientização, como se espera de uma formação baseada na pedagogia crítica (SILVA, 1999). Essas questões estavam presentes nos conteúdos e foram trazidas ao espaço a partir de discussões e reflexões sobre a prática cotidiana dos educandos (GADOTTI, 2009; SINGER, 2005; FREIRE, 1989). Os temas tratados nos módulos permitiram aos estudantes compreender o contexto sócio-político em que vivem e a vislumbrar outras possibilidades de vida, não se resignando ou se adequando à realidade do mercado de trabalho (SILVA, 1999; GIROUX, 1986).

Os conteúdos com os quais os estudantes puderam interagir são coletâneas de temas para a reflexão da sociedade a partir de diferentes visões com afinidades com a ES crítica. Entende-se que isso os possibilita ter contato com diferentes formas de ver a realidade, o que se entende ser importante para a constituição da própria capacidade crítica do sujeito. A realidade e as experiências são as mediadoras desse processo que ocorre num espaço pedagógico aberto à discussão e à autoaprendizagem mútua (SINGER, 2005). 0 questionamento de determinados conteúdos e conhecimentos, bem como a denúncia de formas de opressão e reprodução das estruturas de dominação, também tiveram lugar na experiência pedagógica estudada. Os temas tratados partiam da crítica a algum conhecimento estabelecido ou de alguma prática ou estrutura de dominação na sociedade capitalista e de como isso estava ligado à realidade vivenciada por cada um (SILVA, 2004).

No espaço educativo e nos espaços complementares extraclasse, foram ensejadas atividades com afinidade à proposta pedagógica do curso como feira de trocas, forró, caldo e a auto-organização em grupos para realização das atividades. Isso é importante especialmente quando se tem em conta que os espaços educativos escolares ensinam não só conteúdos, mas formas de se comportar (GIROUX, 1986). 0 curso incentivou a participação e a auto-organização dos estudantes e a prática (SINGER, 2005; GADOTTI, 2009). Outra postura bastante incentivada foi a solidariedade e a preocupação com o outro, além da consciência coletiva e solidária do homem, pilar fundamental da educação crítica (FREIRE, 1989), não só apenas na reflexão, mas na vivência prática.

\section{Considerações finais}

A pesquisa realizada evidenciou que nos três momentos da política analisada há considerável consonância dos sentidos de emancipação em torno da ES crítica. Notou-se, com algumas variações, a presença da busca por emancipação em suas três dimensões: superação da alienação do trabalho capitalista; emancipação político-pragmático; emancipação utópico-ontológica. Ressalta-se o aparecimento da ES neoliberal no material 
do curso devido à ambiguidade do discurso e ao risco de que as iniciativas de ES, dada sua fragilidade no Brasil, sirvam para ocultar uma forma de exploração aumentando a precarização do trabalho. Outras diferenças foram encontradas no material do curso devido à ênfase e propósito de cada comunicação.

Extrapolando os sentidos da ES nos três momentos e se detendo na sala de aula, notou-se que o curso tem grande potencial emancipatório no sentido da ES crítica, já que se aproxima bastante de uma proposta de educação e formação críticas. Essa formação tem como objetivo a autonomia crítica, a noção de coletividade, o valor da solidariedade, a construção de relações horizontais, a busca por uma democracia radical, o fim de todas as formas de opressão, a aposta em processos pedagógicos pelo diálogo, com autonomia e auto-organização dos estudantes e, enfim, a emancipação humana.

A referida consonância indica, portanto, o potencial do curso e que há possibilidade de ganhos na entrada da ES no Estado. No entanto, a moderação do discurso da Senaes nos textos de referência, embora sem impacto perceptível no curso, são indícios de limitação da ação por dentro do Estado.

Entende-se que adoção de um discurso mais palatável guarda relação com o baixo orçamento da Senaes e com o intento de ampliação de parcerias para ter acesso a mais recursos e aumentar a visibilidade da ES no Governo Federal. Nagem e Silva (2013) mostram que o orçamento da Senaes teve em média 0,09\% do total do Ministério do Trabalho e Emprego (MTE) entre 2004 e 2011, e que o Programa de Qualificação Social e Profissional do MTE teve dotação orçamentária em 2010 cinco vezes maior que o PESD, programa em que estão as políticas de ES da Senaes (NAGEM; SILVA, 2013). Assim, seria possível dizer que a Senaes adota um discurso com críticas menos diretas ao capitalismo no intento de alargar suas possibilidades de parcerias com organizações do Executivo Federal, dos diferentes entes federados e da sociedade civil que não sejam necessariamente radicais, mas que possam ter afınidades com algumas das bandeiras da ES. Exemplo de algumas dessas parcerias são o Pronasci Economia Solidária (Ministério da Justiça), o Fomento para a Organização de Cooperativas Atuantes com Resíduos Sólidos (Ministério das Cidades) e a parceria com o Ministério da Ciência e Tecnologia para o apoio ao Programa Nacional de Incubadoras de Cooperativas Populares (Proninc).

Não obstante, a moderação do discurso pode indicar mais do que a vontade ou necessidade de parcerias, mas uma limitação de propostas mais radicais por dentro do Estado. Nagem e Silva (2013) mostram como as fragilidades das políticas de ES geram efeitos nas possibilidades de atuação da secretaria e a submetem aos objetivos do MTE e de outros setores do Governo Federal: "a política vive em um estado de instabilidade, necessitando constantemente de negociações diversas com a cúpula de governo" (NAGEM; SILVA, 2013, p. 171). 0 efeito disso nas ações da Senaes é que "o fortalecimento do mercado de trabalho assalariado permaneceu como prioridade do governo, cabendo à Senaes apenas um papel residual, quase simbólico" (NAGEM; SILVA, 2013, p. 171). Segundo Nagem e Silva (2013) enquanto a ES for encarada meramente como uma alternativa paliativa ao problema do desemprego pelo Governo Federal dificilmente conseguirá se colocar como uma alternativa ao capitalismo. 
A partir do que foi possível notar entre as possibilidades e limitações das ações da ES via Estado, é preciso considerar que há tanto limites quanto possibilidades. Em relação à cooptação e deturpação dos objetivos da ES dentro do Estado, parece ser fundamental que o movimento de ES mantenha sua autonomia, observando uma linha de organização e de ação independente do aparato estatal, mas sem abrir mão de disputar espaços e recursos nessa esfera.

\section{Referências}

ADAMS, Telmo. Educação e economia popular solidária: mediações pedagógicas do trabalho associado. Aparecida: Idéias \& Letras, 2007.

ANDRÉ, Marli Eliza. Etnografia da prática escolar. 13. ed. Campinas: Papirus, 2007.

BARBOSA, Rosangela Nair de Carvalho. A economia solidária como política pública: uma tendência de geração de renda e ressignificação do trabalho no Brasil. São Paulo: Cortez, 2007.

BARDIN, Laurence. Análise de conteúdo. Lisboa: Edições 70, 2009.

BRASIL. Ministério do Trabalho e Emprego. Secretaria Nacional de Economia Solidária. Seleção de instituições para implantação de Centros de Formação em Economia Solidária - CFES (2007 a 2010). Brasília, DF: Senaes, 2007. Disponível em: <http://www.mte.gov.br/ecosolidaria/prog_selecao_insti_ cfes_2007_4.pdf>.Acesso em: 03 out. 2009.

BRASIL. Ministério do Trabalho e Emprego. Secretaria Nacional de Economia Solidária. 0 que é economia solidária. Brasília, DF: Senaes, [s. d.]. Disponível em: <http://www.mte.gov.br/ecosolidaria/ecosolidaria_ oque.asp>. Acesso em: 28 set. 2011.

CALBINO, Daniel. A educação na economia solidária: possibilidade para um novo paradigma social. Revista Brasileira de Desenvolvimento Regional, Taubaté, v. 9, n. 2, p. 301-324, maio/ago. 2013.

CANÇADO, Airton Cardoso. Para a apreensão de um conceito de cooperativa popular. In: ENCONTRO NACIONAL DA ANPAD, 29., 2005. Brasília, DF. Anais... Brasília, DF: Anpad,2005. 1 CD-ROM.

CASTELLS, Manuel. Redes de indignação e esperança: movimentos sociais na era da internet. Rio de Janeiro: Zahar, 2013.

CECCON, Claudius (Coord.). Outra economia acontece. Documentário, 25'26". Direção: Thereza Jessouroun. Apoio: Fundação Banco do Brasil, Ministério do Trabalho e Emprego, Governo Federal e Fome Zero. Realização: Fórum Brasileiro de Economia Solidária e Secretaria Nacional de Economia Solidária.

CONFERÊNCIA NACIONAL DE ECONOMIA SOLIDÁRIA (CONAES), 2., 2010, Brasillia, DF. Documento final. Brasília, DF: Senaes/MTE, 2010. Disponível em: <http://www.ipea.gov.br/participacao/images/pdfs/ conferencias/Economia_Solidaria_II/deliberacoes_2_conferencia_economia_solidaria.pdf>. Acesso em: 24 nov. 2010. 
CORAGGI0, José Luis. Introducción. In: CORAGGI0, José Luis. La economía social desde la periferia: contribuiciones latinoamericanas. Buenos Aires: Altamira, 2007. p. 17-57.

COSTA, Bianca A. Lima; JESUS, Paulo. A economia solidária no Brasil: uma trajetória de conformação enquanto movimento social? Revista Mundo do Trabalho Contemporâneo, Brasília, DF, v. 2, n. 2, p. 241 264, 2017.

DAGNINO, Renato; NOVAES, Henrique Tahan. As forças produtivas e a transição ao socialismo: contrastando as concepções de Paul Singer e István Mészáros. Org \& Demo, Marília, v. 8, n. 1/2, p. 60-80, 2007.

ENGUITA, Marino Fernández. A face oculta da escola: educação e trabalho no capitalismo. Porto Alegre: Artmed, 1989.

FARIA, Ana Lúcia Goulart de. Ideologia no livro didático. São Paulo: Cortez, 1994.

FÓRUM BRASILEIRO DE ECONOMIA SOLIDÁRIA (FBES), 2010. A trajetória do movimento da economia solidária no Brasil: do Fórum Social Mundial (FSM) ao Fórum Brasileiro de Economia Solidária (FBES). [S. I.: s. n.], 2010. Disponível em: <http://www.itcp.coppe.ufrj.br/rede_gestores/pdfs/5_principios.pdf>. Acesso em: 24 de nov. de 2010.

FRANÇA FILHO, Genauto Carvalho. Teoria e prática em economia solidária: problemática, desafios e vocação. Revista de Ciências Sociais, Porto Alegre, v. 7, n. 1, p. 155-174, jan./jul. 2007.

FREIRE, Paulo. A importância do ato de ler: três artigos que se completam. São Paulo: Cortez, 1989.

FREIRE, Paulo. Pedagogia do oprimido. Porto Alegre: Artmed, 2002.

FREITAG, Bárbara. 0 livro didático em questão. São Paulo: Cortez, 1993.

GAD0TTI, Moacir. Economia solidária como práxis pedagógica. São Paulo: Instituto Paulo Freire, 2009.

GAIGER, Luis Inácio. A economia solidária diante do modo de produção capitalista. Caderno CRH, Salvador, n. 39, p. 181-211, jul./dez. 2003.

GAIGER, Luis Inácio. La economia solidaria y el capitalismo en la perspectiva de las transiciones históricas. In: CORAGGI0, José Luis. La economía social desde la periferia: contribuiciones latinoamericanas. Buenos Aires: Altamira, 2007. p. 79-110.

GIROUX, Henry. Cruzando as fronteiras do discurso educacional: novas políticas em educação. Porto Alegre: Artmed, 1999.

GIROUX, Henry. Teoria crítica e resistência em educação: para além das teorias de reprodução. Petrrópolis: Vozes, 1986.

IMS. Centro de Formação em Economia Solidária da Região Sudeste - CFES/SE (2008-2010). [S. I.: S. n.], 2008. Disponível em: <https://cirandas.net/cfes-rj/o-projeto/o-projeto?view=true>. Acesso em: 18 dez. 2010. 
IPEA - Instituto de Pesquisa Econômica Aplicada. 0s novos dados do mapeamento de economia solidária no Brasil: nota metodológica e análise das dimensões socioestruturais dos empreendimentos. Brasília, DF: IPEA, 2016.

LAVILLE, Jean Luis et al. Introdução. In: FRANÇA FILHO, Genauto Carvalho de et al. (Org.). Ação pública e economia solidária: uma perspectiva internacional. Porto Alegre: UFRGS, 2006. p. 11-18.

LIMA, Jacob Carlos. As artimanhas da flexibilização: 0 trabalho terceirizado em cooperativas de produção. São Paulo: Terceira Margem, 2002.

LIMA, Jacob Carlos. Cooperativas, trabalho associado, autogestão e economia solidária: a constituição do campo de pesquisa no Brasil. In: GEORGES, Isabel Pauline Hildegard; LEITE, Marcia de Paula (Org.). Novas configurações do trabalho e economia solidária. São Paulo: Annablume, 2009. p. 195-226.

MANCE, Euclides André. Economia solidária: um novo paradigma? In: SEMINÁRIO CATARINENSE DE ECONOMIA SOLIDÁRIA, 1., 2000. Florianópolis. Anais. Florianópolis: SCES, 2000. Disponível em: <http:// www.solidarius.com.br/mance/biblioteca/economia2.htm>. Acesso: mar. 2012.

MCLAREN, Peter. A vida nas escolas: uma introdução à pedagogia crítica nos fundamentos da educação. Porto Alegre: Artes Médicas, 1997.

MINAYO, Maria Cecília de Souza. 0 desafio do conhecimento: pesquisa qualitativa em saúde. 3. ed. São Paulo: Rio de Janeiro: Hucitec-Abrasco, 1994.

Motta, Eugênia de Souza Mello Guimarães. A "outra economia": um olhar etnográfico sobre a economia solidária. 2004. Dissertação (Mestrado em Antropologia Social) - Universidade Federal do Rio de Janeiro (UFRJ). Rio de Janeiro, 2004.

NAGEM, Fernanda Abreu; SILVA, Sandro Pereira. Institucionalização e execução das políticas públicas de economia solidária no Brasil. Revista de Sociologia Política, Curitiba v. 21, n. 46, p. 159-175, 2013.

NOSELLA, Maria de Lourdes Chagas Deiró. As belas mentiras: a ideologia subjacente aos textos didáticos. São Paulo: Moraes, 1979

PERRITON, Linda; REYNOLDS, Michael. Critical management education: from pedagogy of possibility to pedagogy of refusal? Management Learning, London, v. 35, n. 1, p. 61-77, 2004.

POCHMANN, Marcio. Estado e capitalismo no Brasil: a inflexão atual no padrão das políticas públicas do ciclo político na nova república. Educação \& Sociedade, Campinas, v. 38, n. 139, p. 309-330, 2017.

POCHMANN, Marcio. 0 trabalho sob fogo cruzado: exclusão, desemprego e precarização no final do século. 3. ed. São Paulo: Contexto, 1999.

REIS, Fábio Wanderley. Teoria e sociedade brasileira. In: REIS, Fábio Wanderley. Mercado e utopia: teoria política e sociedade brasileira. São Paulo: Edusp, 2000. p. 229-256. 
SÁ-SILVA, Jackson Ronie; ALMEIDA, Cristóvão Domingos; GUINDANI, Joel Felipe. Pesquisa documental: pistas teóricas e metodológicas. Revista Brasileira de História e Ciências Sociais, Santa Vitória do Palmar, v. 1, n. 1, p. 1-15, jul. 2009.

Schwartzman, Simon. Representação e cooptação política no Brasil. Dados Revista de Ciências Sociais, Rio de Janeiro, v. 7, p. 9-41, 1970.

SILVA, Antônio Ozaí da. Pedagogia libertária e pedagogia crítica. Revista Espaço Acadêmico, Maringá, n. 42, nov. 2004.Disponível em: <http://www.espacoacademico.com.br/042/42pc_critica.htm>. Acesso em: 21 mar. 2011.

SILVA, Tomaz Tadeu. Documentos de identidade: uma introdução às teorias do currículo. Belo Horizonte: Autêntica, 1999.

SINGER, Paul. A economia solidária como ato pedagógico. In: KRUPPA, Sonia M. Portella (Org.). Economia solidária e educação de jovens e de adultos. Brasília, DF: INEP/MEC, 2005. p. 15-20.

SINGER, Paul. Introdução a economia solidária. São Paulo: Fundação Perseu Abramo, 2002.

Vídeo Institucional outra economia acontece. Produção: Casanova Filmes. Apoio: Fundação Banco do Brasil, Ministério do Trabalho e Emprego, Governo Federal e Fome Zero. Realização: Fórum Brasileiro de Economia Solidária e Secretaria Nacional de Economia Solidária. Documentário, 11'52". s/d.

WELLEN, Henrique André Ramos. Contribuição à crítica da 'economia solidária'. Revista Katálysis, Florianópolis, v. 11, n. 1, p. 105-115, 2008.

ZITKOSKI, Jaime José. Educação popular e economia solidária: um diálogo possível e necessário. Diálogo, Canoas, n. 17, p. 97-106, jul./dez. 2010.

Recebido em: 06.09.2017

Revisões em: 14.06.2018

Aprovado em: 07.08.2018

Felipe Marques Carabetti Gontijo é doutorando na linha de pesquisa de estudos organizacionais e sociedade no Centro de Pós-graduação e Pesquisa em Administração (CEPEAD) da Universidade Federal de Minas Gerais (UFMG) e pesquisador do Núcleo de Estudos Organizacionais e Sociedade (NEOS).

Ana Paula Paes de Paula é doutora em ciências sociais pelo Instituto de Filosofia e Ciências Humanas da Universidade Estadual de Campinas (Unicamp). É professora titular da Faculdade de Ciências Econômicas e do Centro de Pós-Graduação e Pesquisa em Administração (CEPEAD) da Universidade Federal de Minas Gerais (UFMG). 